\title{
Chemical Aspects of Nanoparticle Ecotoxicology
}

\author{
Laura Sigg ${ }^{\text {ab }}$, Renata Behra ${ }^{\mathrm{a}}, \mathrm{Ksenia}_{\text {Groh }}^{\mathrm{ac}}$, Carl Isaacson ${ }^{\mathrm{ae}}$, Niksa Odzaka, Flavio Piccapietra ${ }^{\text {ad }}$, \\ Lena Röhder ${ }^{\mathrm{ab}}$, Hannah Schuga ${ }^{\mathrm{a}}$, Yang Yue ${ }^{\text {af }}$, and Kristin Schirmer ${ }^{\mathrm{abf}}$
}

\begin{abstract}
Nanoecotoxicology strives to understand the processes and mechanisms by which engineered nanoparticles (ENP) may exert toxic effects on aquatic organisms. Detailed knowledge of the chemical reactions of nanoparticles in the media and of their interactions with organisms is required to understand these effects. The processes of agglomeration of nanoparticles, of dissolution and release of toxic metal ions, and of production of reactive oxygen species (ROS) are considered in this article. Important questions concern the role of uptake of nanoparticles in various organisms, in contrast to uptake of ions released from nanoparticles and to nanoparticle attachment to organism surfaces. These interactions are illustrated for effects of silver nanoparticles (AgNP), cerium oxide $\left(\mathrm{CeO}_{2} \mathrm{NP}\right)$ and titanium dioxide $\left(\mathrm{TiO}_{2} \mathrm{NP}\right)$, on aquatic organisms, including algae, biofilms, fish cells and fish embryos.
\end{abstract}

Keywords: Agglomeration $\cdot$ Cerium oxide $\cdot$ Exposure media $\cdot$ Nanoparticles $\cdot$ Silver

\section{Introduction}

Nanoecotoxicology has been rapidly developing in the last few years, as a response to the tremendous development of nanotechnology, and aims at understanding effects of nanomaterials to ecosystems by considering impacts on various organisms. ${ }^{[1-4]}$ The assessment of environmental effects of engineered nanomaterials requires knowledge of released nanomaterial quantities and their potential distribution in environmental compartments. ${ }^{[5-7]}$ This knowledge constitutes the basis to estimate the availability of nanomaterials to interact with organisms living in exposed environments. In particular, concerns about possible effects of engineered nanoparticles

\footnotetext{
${ }^{*}$ Correspondence: Prof. Dr. L. Sigg ${ }^{\text {ab }}$

Tel.: +4158765 5494

E-mail: laura.sigg@eawag.ch

aEawag, Swiss Federal Institute of Aquatic Science

and Technology

P.O. Box 611, CH-8600 Dübendorf

${ }^{\mathrm{b}} \mathrm{ETH}$ Zürich

Institute of Biogeochemistry and Pollutant Dynamics

$\mathrm{CH}-8092$ Zürich

'ETH Zürich

Department of Chemistry and Applied Biosciences

$\mathrm{CH}-8093$ Zürich

dPresent address: McGill University

Departments of Civil Engineering and Chemical

Engineering

Montreal, Canada

ePresent address: Bemidji State University

Department of Environmental Science

Bemidji, MN, USA

'EPF Lausanne, School of Architecture

Civil and Environmental Engineering

$\mathrm{CH}-1015$ Lausanne
}

(ENP) released into the environment have been growing, in parallel to their increased use in consumer products. ${ }^{[1,8,9]}$ Thus, the study of potential ENP effects on organisms is receiving increasing attention, especially concerning aquatic organisms, such as algae, daphnia, or fish. ${ }^{[2,4,10,11]}$

Which engineered nanoparticles are of foremost interest for nanoecotoxicology? Based on the production quantities and potential release into the environment, silver nanoparticles (AgNP), titanium dioxide $\left(\mathrm{TiO}_{2}\right)$, zinc oxide $(\mathrm{ZnO})$, and cerium oxide $\left(\mathrm{CeO}_{2}\right)$ are most likely to cause adverse environmental effects. All these ENP have been increasingly used for various purposes, including in consumer products from which they can easily be released into the aquatic environment.[7,12] Concentrations of ENP in aquatic systems can, however, so far only be estimated on the basis of material flow models. ${ }^{[6,13,14]}$

Standardized toxicity tests have already been used to evaluate ENP toxicity to various model species, but exposure conditions and other parameters have to be carefully adapted for nanomaterials. ${ }^{[1]}$ However, questions of interest for nanoecotoxicology extend far beyond simple testing of nanoparticles and include the processes and mechanisms by which ENP may exert toxic effects to aquatic organisms. ${ }^{[2,15]}$ Important questions concern the role of uptake of nanoparticles by various organisms, in contrast to uptake of ions released from nanoparticles. ENP may also exert effects by interactions at the interfaces of organisms, by specific interactions with functional groups or by unspecific attachment by physical adhesion processes, or by production of reactive oxygen spe- cies (ROS) in the external medium, at the interface between organism and medium, or inside organisms.

We illustrate in the following the crucial role of chemical aspects to better understand nanoecotoxicology, in particular with respect to the effects of various ENP, such as $\mathrm{AgNP}, \mathrm{CeO}_{2} \mathrm{NP}$ and $\mathrm{TiO}_{2} \mathrm{NP}$, on aquatic organisms, including algae, biofilms, fish cells and fish embryos. Agglomeration state of ENP in the media used for exposure of organisms is an important parameter requiring careful evaluation. The role of dissolution leading to the release of toxic metal ions is another relevant process, especially for AgNP, but also for other nanoparticles. ${ }^{[16]}$ Furthermore, reactions at the nanoparticle surfaces, which lead to the production of ROS, are discussed below.

\section{Nanoparticle and Colloidal Size Range}

The conventional definition of engineered nanomaterials specifies that those have a size $<100 \mathrm{~nm}$ in at least one dimension.[17] The ENP described here are usually $<100 \mathrm{~nm}$ in all three dimensions, in their nominal size upon production. In many cases, the NP size measured under conditions of a suspension in experimental exposure media or in natural waters is higher than this nominal size. It is important to recognize that this size range corresponds to the range usually defined as 'colloidal' for natural waters. ${ }^{[18]}$ ENP in the nanometer size range are characterized by high specific surface areas and thus high surface reactivity. 
With regard to fate in natural waters and effects of ENP to organisms, the distinction between dissolved species, nanoparticles or colloidal particles, and the particulate size range is of significance. Dissolved species include metal ions and metal complexes with inorganic ions or with simple organic molecules, up to a size range of about $1 \mathrm{kDa}$. The colloidal size range is operationally defined in natural waters as the range over $1 \mathrm{kDa}$, corresponding to a size of few nanometers, and smaller than $450 \mathrm{~nm}-1 \mu \mathrm{m}$ (size range of usual filtration), whereas particles larger than the usual filter pore size of $450 \mathrm{~nm}$ or $1 \mu \mathrm{m}$ are considered as the particulate range. ENP with a size $<100 \mathrm{~nm}$ thus fall into the colloidal size range.

Analytical distinction between the nanoparticle and dissolved size range may be achieved by ultrafiltration, ultracentrifugation, DGT (Diffusive Gradients in Thin films) and other membrane techniques (see below).

\section{Characterization of Nanoparticles in Ecotoxicological Studies}

The following chemical and physical aspects of ENP characterization need to be considered for their evaluation in ecotoxicological studies: size distribution and agglomeration in exposure media, dissolution releasing metal ions into solution, interactions with ligands, redox reactions at ENP surfaces and ROS formation, and surface transformation reactions. These aspects will be illustrated with examples from our research.

\subsection{ENP Size Distribution, Surface Charge and Agglomeration}

To examine interactions of ENP with aquatic organisms, a prerequisite is the knowledge of the size distribution of ENP in the medium in which organisms are exposed to ENP. ENP suspensions are stabilized by their surface charge and/or by steric stabilization due to coatings of macromolecules. An important question is whether organisms are exposed to welldispersed ENP with small size or to agglomerates or aggregates of larger size. ${ }^{[3]}$ ENP in agglomerates are only weakly bound, e.g. by agglomeration due to high ionic strength, whereas in aggregates they are fused together and cannot be easily dispersed. ${ }^{[17]}$ Exposure media often need to be adapted to obtain well-defined exposure conditions with a narrow size distribution of well-dispersed ENP. ${ }^{[1,3]}$

AgNP coated with carbonate or citrate are stabilized by their negative surface charge in a broad pH-range. To study the effects of carbonate-coated AgNP to the alga Chlamydomonas reinhardtii, a simple medium with the buffer MOPS (3-morpholine propanesulfonic acid, $10 \mathrm{mM}$ ) at $\mathrm{pH}$ 7.5 was used.[19] AgNP were stable with respect to their size in this medium, with an average size around $30 \mathrm{~nm}$, and were negatively charged due to the carbonate coating (Fig. 1a). If the $\mathrm{pH}$ shifts to lower values $(\mathrm{pH}<5)$, the carbonate coating is protonated and the zeta potential becomes less negative and tends towards $0 \mathrm{mV}$, so that the AgNP agglomerate to sizes $>1 \mu \mathrm{m}$.

In the case of AgNP effects on fish cell cultures, an exposure medium with a higher ionic strength has to be used. [20] Furthermore, media for fish cell cultures usually contain high concentrations of chloride, which may lead to complex formation with $\mathrm{Ag}^{+}$and precipitation of $\mathrm{AgCl}(\mathrm{s})$. Citrate-coated $\mathrm{AgNP}$ were stable with respect to average size and zeta potential over 24 hours in an optimized medium with lower ionic strength, calcium and chloride concentrations $(\mathrm{I}=0.072, \mathrm{pH}$ 7.1-7.4, $\mathrm{Cl}^{-}=0.5 \mathrm{mM} .{ }^{[20]}$ Fig. 1b). The average size of citrate-coated AgNP was in this case $50-100 \mathrm{~nm}$. In a similar way, an exposure medium with low chloride concentration $(0.05 \mathrm{mM})$ was developed for exposure of zebrafish embryos to AgNP, [21] in which the average size of carbonate coated AgNP remained smaller than 100 $\mathrm{nm}$ for $24 \mathrm{~h}$.

In the case of uncoated $\mathrm{CeO}_{2} \mathrm{NP}$, the surface charge depends on the acid-base reactions at the NP surfaces. The iso-electric point of $\mathrm{CeO}_{2} \mathrm{NP}$ is in the range of $\mathrm{pH}$ 6.5-8. It is thus difficult to stabilize $\mathrm{CeO}_{2}$ NP in culture media in the pH-range 7-8. To study effects of $\mathrm{CeO}_{2} \mathrm{NP}$ on algae, a medium containing MOPS $(10 \mathrm{mM})$ with the addition of phosphate $(50 \mu \mathrm{M})$ was developed, in which phosphate stabilized these NP at $\mathrm{pH} 7.5$ by building up a negative surface charge. [22] In a similar way as with other metal oxides, phosphate is likely binding by anion adsorption to the surface of $\mathrm{CeO}_{2}$ NP. The average size of the $\mathrm{CeO}_{2} \mathrm{NP}$ was stable at about $150 \mathrm{~nm}$ in this medium, thus somewhat higher than the original size of the primary NP, which was given as $25 \mathrm{~nm}$ by the producer, but much lower than in the medium without phosphate (Fig. 1c). This larger size was likely due to the formation of aggregates with few NP, which cannot be readily dispersed further.

$\mathrm{TiO}_{2}$ NP have an iso-electric point in the neutral $\mathrm{pH}$-range and are thus not stabilized with respect to their size in typical exposure media. Large agglomerates $(>1$ $\mu \mathrm{m})$ are formed in the presence of divalent ions, such as $\mathrm{Ca}^{2+}$ and $\mathrm{Mg}^{2+}$ at concentrations representative of freshwaters. ${ }^{[23,24]}$ However, in media which were simulating freshwater composition by a combination of major ions and fulvic and humic acids

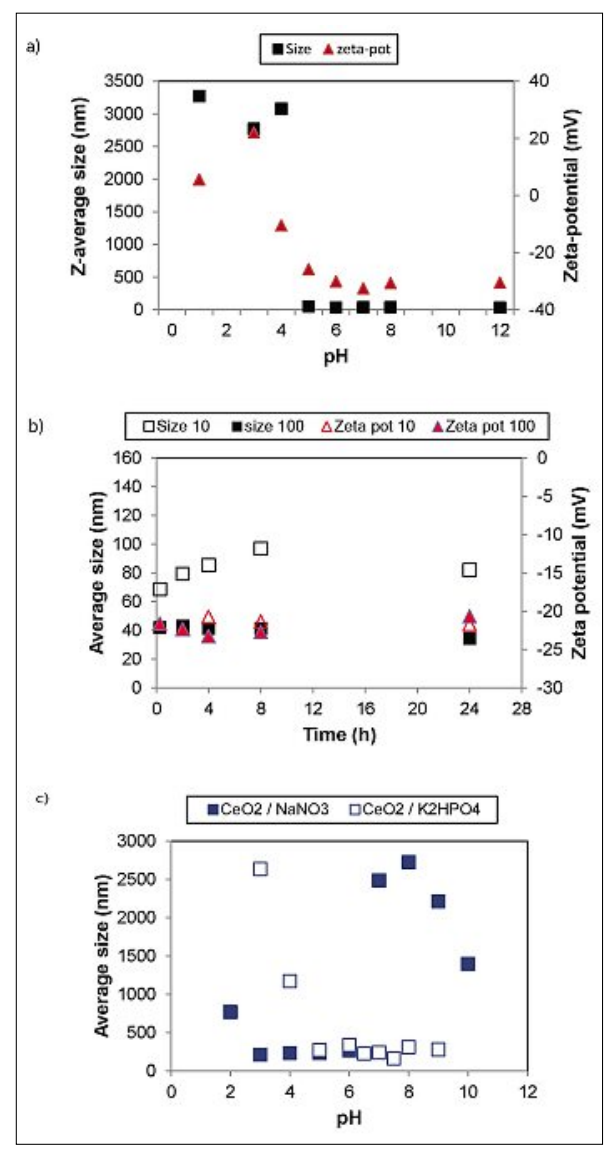

Fig. 1. Average size of AgNP and of $\mathrm{CeO}_{2}$ NP in media used for algae and for fish cell cultures (3 replicates each), as determined by DLS (dynamic light scattering). a) Average size (left scale) and zeta potential (right scale) of carbonate-coated AgNP $(100 \mu \mathrm{M})$ as a function of $\mathrm{pH}$ in $10 \mathrm{mM}$ MOPS used for algae exposure (Piccapietra et al. ${ }^{[19]}$ ); b) Average size (left scale, white $(10 \mu \mathrm{M})$ and filled $(100 \mu \mathrm{M})$ squares) and zeta potential (right scale, white $(10 \mu \mathrm{M})$ and filled (100 $\mu \mathrm{M})$ triangles) of citrate-coated AgNP in a medium used for fish cell exposure as a function of time over $24 \mathrm{~h}$ (Yue et al. ${ }^{[20]}$ ); c) Average size of $\mathrm{CeO}_{2} \mathrm{NP}$ in $1 \mathrm{mM} \mathrm{NaNO}_{3}$ as a function of $\mathrm{pH}$ in the absence (filled squares) and presence of phosphate (white squares) (after Röhder et al. ${ }^{[22]}$ ).

(5 $\mathrm{mg} \mathrm{L}^{-1} \mathrm{FA}$ and HA), $\mathrm{TiO}_{2} \mathrm{NP}$ were stabilized to a size of about $600 \mathrm{~nm}$ over one week. ${ }^{[24]}$ Fulvic acids with lower molecular weight were more efficient in stabilizing $\mathrm{TiO}_{2} \mathrm{NP}$ than the larger humic acids.

\subsection{Dissolution of Nanoparticles}

Dissolution of ENP is of foremost interest for their interactions with organisms, as dissolved metal ions, such as $\mathrm{Ag}^{+}, \mathrm{Cu}^{2+}$, $\mathrm{Zn}^{2+}$ are well known to be bioavailable and potentially toxic to aquatic organisms.[25] Dissolved metal ions as a function of medium composition have thus to be investigated in ENP exposure experiments. In particular, the role of $\mathrm{Ag}^{+}$ions in $\mathrm{AgNP}$ suspensions has to be carefully evaluated, as $\mathrm{Ag}^{+}$ions are highly toxic to algae and to other organisms. ${ }^{[16,26,27]} \mathrm{AgNP}$ suspensions 
usually contain residual $\mathrm{Ag}^{+}$ions from synthesis. Additionally, AgNP can dissolve by oxidation to $\operatorname{Ag}(\mathrm{I})$, as a function of $\mathrm{pH}$, presence of ligands and of oxidants in the media. Dissolved $\mathrm{Ag}(\mathrm{I})$ includes $\mathrm{Ag}^{+}$ions and complexes with the available ligands.

Among the various ligands of interest for $\mathrm{Ag}^{+}$, chloride plays a special role, because it is present at high concentrations in media used for various organisms, as well as in natural waters. Chloride forms with $\mathrm{Ag}^{+}$the solid phase $\mathrm{AgCl}(\mathrm{s})$ (with log $\left.\mathrm{K}_{\mathrm{s} 0}=-9.75\right)$, and the complexes $\mathrm{AgCl}^{\circ}(\mathrm{aq})$, $\mathrm{AgCl}_{2}^{-}, \mathrm{AgCl}_{3}^{2-}$. Depending on the chloride concentration, chloride may thus lead to an increase in dissolved $\operatorname{Ag}(\mathrm{I})$ with dissolved chloro-complexes, or to precipitation of $\mathrm{AgCl}(\mathrm{s})$, possibly also at the surface of AgNP. ${ }^{[16]}$ In the case of citratecoated AgNP in fish cell culture media, ${ }^{[20]}$ higher dissolved $\operatorname{Ag}(\mathrm{I})$ concentration was measured in the medium with the highest $\mathrm{Cl}^{-}$concentration $(170 \mathrm{mM})$, than in the diluted medium with $0.5 \mathrm{mM} \mathrm{Cl}^{-}$, or in the medium without $\mathrm{Cl}^{-}$(Fig. 2a). Equilibrium calculations indicated that in the medium with the highest $\mathrm{Cl}^{-}$concentration, dissolved $\operatorname{Ag}(\mathrm{I})$ would be mostly present as negatively charged complexes $\mathrm{AgCl}_{2}^{-}$and $\mathrm{AgCl}_{3}^{2-}$, but would not be oversaturated with respect to $\mathrm{AgCl}(\mathrm{s})$. A comparison of media used for zebrafish embryos indicated that the chloride concentration plays an important role in modulating the toxicity of AgNP through interfering with dissolved $\operatorname{Ag}(\mathrm{I}){ }^{[21]}$ Higher chloride concentrations generally resulted in lower $\mathrm{Ag}(\mathrm{I})$ and AgNP toxicity to zebrafish embryos ${ }^{[21]}$ and to a fish gill cell line.[20]

Thiol ligands, such as cysteine, mercaptoethanol or glutathione form very stable complexes with $\operatorname{Ag}(\mathrm{I}) .^{[28]}$ These ligands are thus likely to also influence dissolution of AgNP. However, interactions of
AgNP and Ag(I) with thiol ligands involve not only dissolution reactions, but also reduction reactions of $\operatorname{Ag}(\mathrm{I})$ and formation of polymers. ${ }^{[29]}$ Dissolution of AgNP in the presence of cysteine indicated both an initial increase of dissolved $\mathrm{Ag}$ and a decrease after longer reaction times (Fig. $2 \mathrm{~b}$, Sigg and Lindauer in preparation). Low $\mathrm{pH}$ is expected to increase and accelerate dissolution of AgNP. AgNP were observed to dissolve faster and to a larger extent in natural waters with lower $\mathrm{pH}$ (Fig. 2c), ${ }^{[30]}$ although additional factors such as presence of ligands and ionic strength may also play a role.

Dissolution of $\mathrm{CeO}_{2} \mathrm{NP}$ is expected to only occur upon reduction to $\mathrm{Ce}$ (III) or upon detachment of $\mathrm{Ce}$ (III) present at surfaces, as thermodynamic data for $\mathrm{Ce}(\mathrm{IV}) \mathrm{O}_{2}$ indicate very low solubility at neutral $\mathrm{pH} .{ }^{[31]}$ The redox reactions of $\mathrm{Ce}(\mathrm{III}) /$ $\mathrm{Ce}$ (IV) are the basis of the catalytic properties of $\mathrm{CeO}_{2} \mathrm{NP}$. Varying concentrations of $\mathrm{Ce}$ (III) may be present at the NP surfaces. ${ }^{[32]}$ In our study on $\mathrm{CeO}_{2} \mathrm{NP}$ effects on $C$. reinhardtii, measured dissolved $\mathrm{Ce}$ was in the range $0.01-0.05 \%$ of total $\mathrm{Ce}$, thus about $1-10 \mathrm{nM}$ for the concentrations used in media at neutral $\mathrm{pH},{ }^{[22]}$ and was assumed to consist of dissolved Ce(III).

No dissolved species are expected to occur in $\mathrm{TiO}_{2} \mathrm{NP}$ suspensions at neutral $\mathrm{pH}$, as the solubility of $\mathrm{TiO}_{2}$ is very low. ${ }^{[33]}$ In contrast, very high solubility of $\mathrm{ZnO}$ nanoparticles was observed, [34] which leads in many cases to complete dissolution to $\mathrm{Zn}^{2+}$.

The results with respect to dissolved concentrations mentioned above were obtained using several different methods to separate nanoparticles from dissolved species, which all need to be critically evaluated for various conditions and media. It is useful to combine several methods to distinguish dissolved from nanoparticle species and to test for bias of the various methods. ${ }^{[20,34]}$ Ultrafiltration is used in many cases, with typical cut-off in the range $1-3 \mathrm{kDa}$, and can be combined with centrifugation for a fast separation of small volumes (e.g. Amicon Ultra Tubes with 3 $\mathrm{mL}$ volume and a cut-off of $3000 \mathrm{Da}$, with centrifugation for $30 \mathrm{~min}$ at $4000 \mathrm{rpm}$ $(1880 \times \mathrm{g})) .{ }^{[26,34]}$ This method is rapid and convenient and allows for determination of time-series over few minutes to hours. However, some drawbacks of this method include possible adsorption of dissolved species to the membranes and retention of larger metal-organic complexes, e.g. metal-protein complexes. Use of ultracentrifugation has to be carefully adapted to ensure that nanoparticles will settle, using e.g. $145^{\prime} 000 \times \mathrm{g}$ and $3 \mathrm{~h}$ centrifugation to separate AgNP in the 20-30 nm size range. [20] In this case, some smaller nanoparticles may still be present in the supernatant. The DGT technique (diffusion gradients in thin films) may also be applied to distinguish between dissolved and nanoparticle species. ${ }^{[34,35]}$ Using DGT, the metal species which are diffusing through a hydrogel are collected on an ion-exchanger. The metal species which are detected are thus defined by their diffusion coefficients in this gel and by the pore size of the hydrogel. Nanoparticles with sizes $>2 \mathrm{~nm}$ are not expected to diffuse through these gels and are thus not detected by DGT. Additionally, complexes with larger organic molecules are also excluded by DGT, so that measured dissolved concentrations by DGT may be somewhat lower in comparison to those obtained by ultrafiltration and ultracentrifugation. [34] The DGT technique gives an average value for dissolved species over time periods of one to several days, which may be useful for experiments

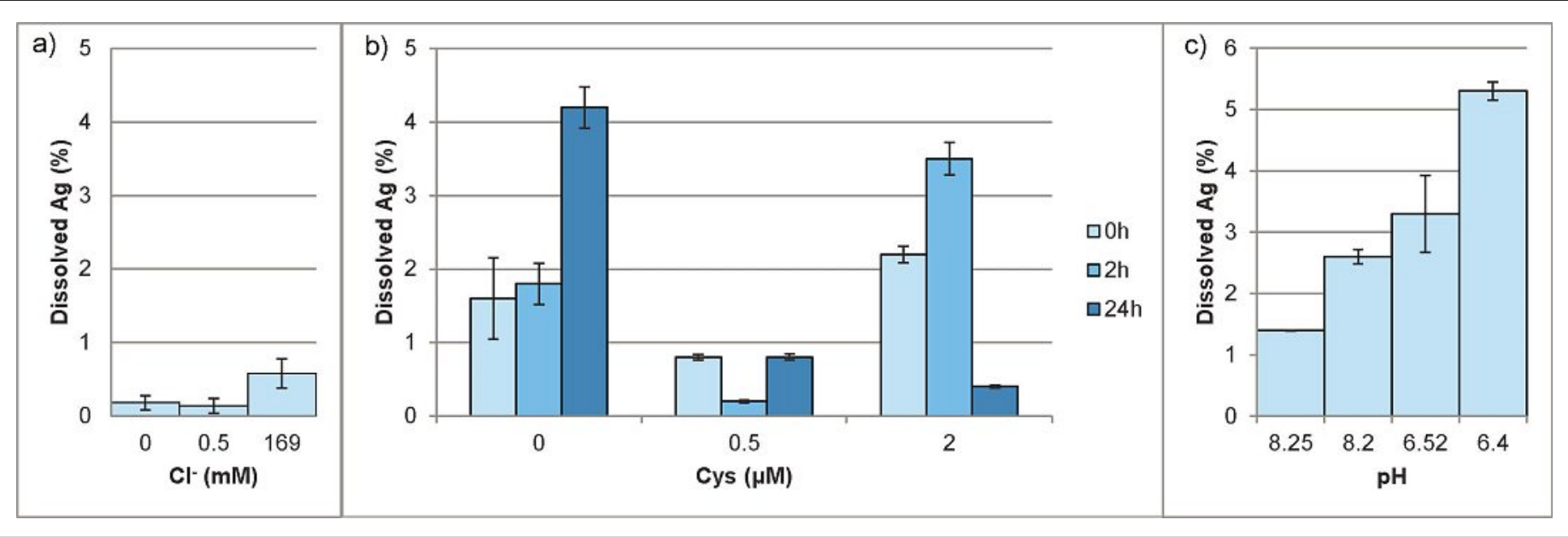

Fig. 2. Dissolved $\mathrm{Ag}^{+}$(\% of total $\mathrm{Ag}$, by ultrafiltration) in AgNP suspensions in various media: a) as a function of chloride concentration in media for fish cells (from Yue et al. ${ }^{[20]}$, average of two AgNP concentrations with two replicates each); b) as a function of cysteine concentration after $0,2 \mathrm{~h}$ or $24 \mathrm{~h}$ (Sigg and Lindauer, unpublished data, average of two replicates each); c) in natural waters with pH in the range 6.4-8.3 (Lake Greifen, pH 8.25; Lake Lucerne, $\mathrm{pH}$ 8.20; Etang de la Gruère, $\mathrm{pH}$ 6.52; Lago Cristallina, $\mathrm{pH} 6.40$; from Odzak et al. ${ }^{[30]}$, average of four replicates each). 
over longer time periods, but does not allow for the detection of rapid variations in dissolved concentrations.

\subsection{Redox Reactions and Formation of ROS Species}

Formation of reactive oxygen species (ROS) species is invoked in many cases as a possible toxicity mechanism for different types of ENP. ${ }^{[36,37]}$ ROS may clearly be formed in the case of ENP with photocatalytic properties, in particular with $\mathrm{TiO}_{2}$, but also with other redox reactive ENP, such as $\mathrm{CeO}_{2} \mathrm{NP}$ and AgNP. ${ }^{[36]}$

$\mathrm{TiO}_{2} \mathrm{NP}$ readily produce $\mathrm{ROS}$ upon interactions with UV-light. ${ }^{[38]}$ These properties of $\mathrm{TiO}_{2}$ are used e.g. for photocatalytic degradation of organic pollutants. ${ }^{[38]}$ However, ROS production may affect aquatic organisms under conditions of natural waters, under which both $\mathrm{TiO}_{2}$ and UV-light are present. The reactivity and colloidal stability of P25 TiO NP and solution-synthesized $\mathrm{TiO}_{2} \mathrm{NP}$ with different surface coatings was compared with respect to their effects on intact heterotrophic biofilms. ${ }^{[23]}$ The photocatalytic activity of these $\mathrm{TiO}_{2} \mathrm{NP}$ was compared by their ability to degrade methylene blue. These reactions indicated that the uncoated $\mathrm{P} 25 \mathrm{TiO}_{2}$ NP had the highest photocatalytic activity, whereas some of the coatings such as catechol, phenylalanine and the dye alizarin red acted as photosensitizers. Tannic acid, which was used as a coating with a structure similar to humic acids, decreased the photocatalytic activity of $\mathrm{TiO}_{2} \mathrm{NP}$. This study thus indicated that the ROS production capacity of $\mathrm{TiO}_{2} \mathrm{NP}$ is modulated by coatings of these NP and in natural systems by interactions with natural organic matter. ROS production by $\mathrm{TiO}_{2} \mathrm{NP}$ may be in particular efficient in shallow streams, in which UV-light may penetrate to the benthic region. Biofilms covering solid substrates in this benthic region may thus be specially affected by $\mathrm{TiO}_{2} \mathrm{NP}$ settling from the overlaying water and interacting with UV-light. [23]

In the case of $\mathrm{CeO}_{2} \mathrm{NP}$, ROS may be either produced or scavenged by the redox reactions with $\mathrm{Ce}(\mathrm{III}) / \mathrm{Ce}(\mathrm{IV})$. $^{[36,39,40]}$ Reaction of $\mathrm{Ce}(\mathrm{III})$ with $\mathrm{H}_{2} \mathrm{O}$ may lead to Fenton-like reactions. ${ }^{[41]}$ Superoxide $\left(\mathrm{O}_{2}{ }^{-}\right)$may on the one hand reduce $\mathrm{Ce}(\mathrm{IV})$ to $\mathrm{Ce}$ (III), and on the other hand oxidize $\mathrm{Ce}(\mathrm{III})$ to $\mathrm{Ce}(\mathrm{IV})$, resulting in the dismutation of superoxide to $\mathrm{H}_{2} \mathrm{O}_{2}$ and $\mathrm{O}_{2} . \mathrm{H}_{2} \mathrm{O}_{2}$, in turn, may react with $\mathrm{Ce}$ (IV) and disproportionate to water and oxygen. ${ }^{[39,40,42]}$ In a study on effects of $\mathrm{CeO}_{2} \mathrm{NP}$ on $C$. reinhardtii, intracellular $\mathrm{ROS}$ formation was measured to examine if effects due to ROS would be of importance. ${ }^{[22]}$ However, no elevated ROS level in the alga $C$. reinhardtii was detected for $\mathrm{CeO}_{2} \mathrm{NP}$ concentrations up to $100 \mu \mathrm{M}$.

\section{Effects of Nanoparticles on Aquatic Organisms: Nanoparticle Specific Effects or Metal Ion Effects?}

To understand how ENP affect aquatic organisms, it is crucial to distinguish if nanoparticles are taken up by the organisms and may lead to specific particle effects, or if effects are mostly due to metal ions released from ENP. The question of nanoparticle uptake in various organisms is thus of essential interest, as in many cases toxic effects are mostly expected if the substances are active within the organism. However, effects due to attachment of ENP to organism surfaces or to ROS formation in the external medium are also possible.

To distinguish between nanoparticle and metal ion effects, several approaches can be used. A comparison of effects of ENP and of the corresponding metal ions is in any case useful and reveals the respective concentration ranges, in which ENP and metal ions are exerting toxic effects, ${ }^{[20,26]}$ Furthermore, addition of ligands which are assumed to rapidly react with the dissolved ions is also helpful for this purpose. In the case of AgNP effects to algae, addition of cysteine as a strong ligand for $\mathrm{Ag}^{+}$ions was efficient in preventing adverse effects of AgNP to photosynthesis. ${ }^{[26]}$ Similarly, cysteine was effective in preventing the toxicity of $\mathrm{Ag}^{+}$and AgNP to zebrafish embryos.[21] However, in the case of AgNP effects to fish cells, addition of the ligands cysteine and 2,3-dimercapto-1-propanesulfonic acid (DMPS) did not completely protect the cells from toxic AgNP effects.[20] These findings indicate that the toxic effects to algae and zebrafish embryos can be attributed to dissolved $\mathrm{Ag}^{+}$ions, whereas some specific particle effects appear to occur in the case of fish cells.

The question of particle or ion effects is closely linked to the question of nanoparticle uptake and internalization in cells of the aquatic organisms. In the case of algae, the cell wall may be an efficient barrier for nanoparticle internalization. Metal ions such as $\mathrm{Ag}^{+}$ions may easily be taken up by metal transporters of essential metal ions, most probably those for $\mathrm{Cu}$ in the case of $\mathrm{Ag}^{+} .{ }^{[16]}$

To distinguish between $\mathrm{AgNP}$ and $\mathrm{Ag}^{+}$ ion uptake in the alga $C$. reinhardtii and between attached and internalized Ag, the algal cells were submitted to a wash procedure before cellular Ag was finally measured by ICP-MS after digestion. ${ }^{[43]} \mathrm{Ag}^{+}$ ions may be either bound to the cell surface ligands or internalized into the cells. Washing cells with a ligand for a short time, in this case with cysteine, allows for a distinction between adsorbed and internalized $\mathrm{Ag}$ after exposure to dissolved
$\mathrm{Ag}^{+}$. Upon exposure to AgNP, nanoparticles may be attached to the surfaces, or possibly internalized, and ions may also be adsorbed or taken up. The wash procedure thus involved several rinsing steps of the algal cells to eliminate loosely attached AgNP at the cell surfaces. Much higher exposure concentrations of AgNP than of dissolved $\mathrm{Ag}^{+}$were needed to reach similar cellular concentrations (Fig. 3). After taking into account uptake of $\mathrm{Ag}^{+}$present in the AgNP suspensions, the number of AgNP bound to cells was calculated based on the mass of AgNP with an average size of $45 \mathrm{~nm}$. Based on these calculations, the conclusions were that only $\mathrm{Ag}^{+}$were internalized and that few AgNP bound to cells were most probably attached NP (Fig. 3).

$\mathrm{CeO}_{2} \mathrm{NP}$ effects on Chlamydomonas reinhardtii were considered for $\mathrm{CeO}_{2} \mathrm{NP}$ in two agglomeration states, as dispersed in a medium with phosphate and as agglomerated without phosphate (Fig. 1c). ${ }^{[22]}$ The low dissolved $\mathrm{Ce}$ in these suspensions was assumed to be $\mathrm{Ce}$ (III), as mentioned above. ${ }^{[22]} \mathrm{No}$ effects of dispersed $\mathrm{CeO}_{2} \mathrm{NP}$ on photosynthesis of $C$. reinhardtii were observed for concentrations up to $200 \mu \mathrm{M}$, whereas a slight decrease of photosynthesis occurred with agglomerated $\mathrm{CeO}_{2} \mathrm{NP}$. These effects were compared to those of $\mathrm{Ce}(\mathrm{III})$ solutions and appeared to be likely due to dissolved $\mathrm{Ce}$ (III), which was expected to be present in solution without phosphate and precipitated in the presence of phosphate.

As mentioned above, effects of $\mathrm{TiO}_{2}$ NP on heterotrophic biofilms appeared to be due to ROS formation, thus to a particle specific effect, which depends on the surface reactivity of these ENP. ${ }^{[23]}$ No effects of dissolved $\mathrm{Ti}$ species are expected because of the very low solubility of $\mathrm{TiO}_{2} \mathrm{NP}$.

\section{Behavior of Engineered Nanoparticles in Natural Waters}

The physical and chemical processes mentioned here are also governing the fate and effects of ENP in natural waters. Exposure of organisms to ENP in experimental media are useful to predict effects in natural waters, but differences in media and natural water composition must be considered. Agglomeration and dissolution processes of ENP strongly depend on the composition of natural waters, in particular as mentioned above, on ionic strength and $\mathrm{pH}$, presence of divalent cations $\left(\mathrm{Ca}^{2+}, \mathrm{Mg}^{2+}\right)$ and of $\mathrm{Cl}^{-}$, concentration and composition of organic matter. ${ }^{[24,30]}$ Agglomeration is predominant at higher ionic strength, whereas dissolved organic matter may contribute to stabilizing ENP in suspension. Dissolution of ENP, in particular of AgNP, may occur depending on 


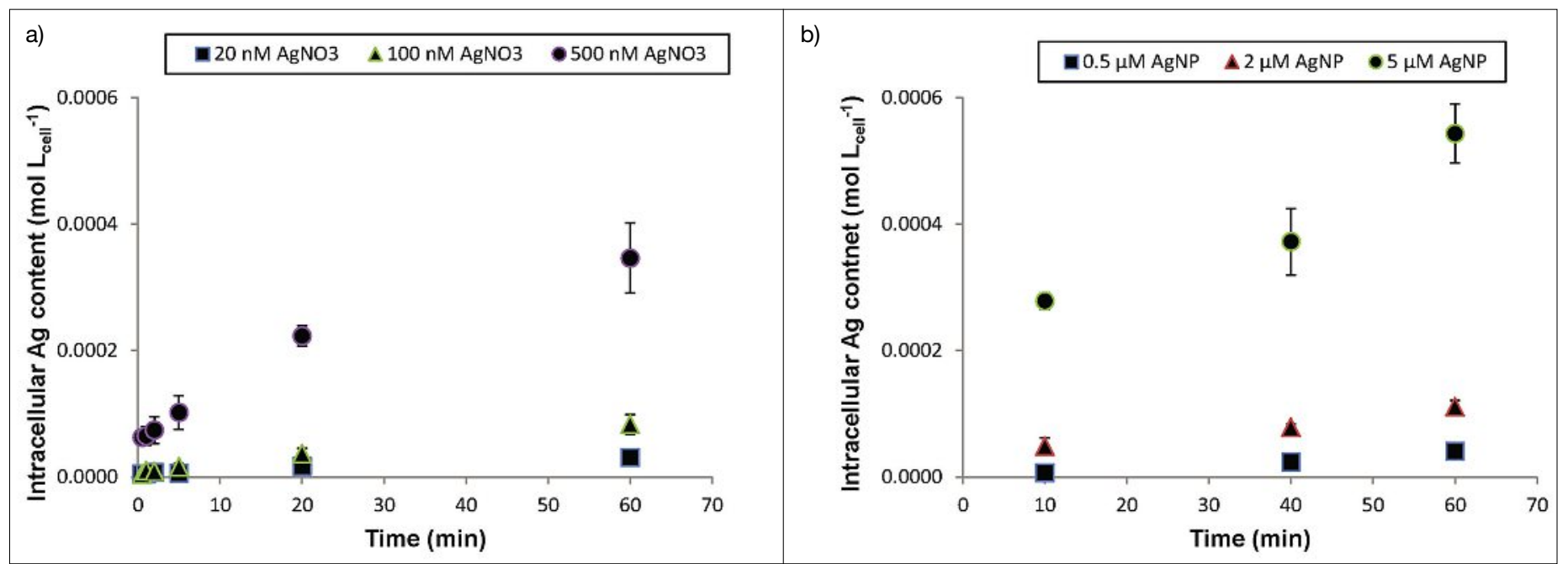

Fig. 3. Intracellular Ag content in Chlamydomonas reinhardtii upon exposure to dissolved $\mathrm{AgNO}_{3}$ (a) and to AgNP (b) as a function of time (3 replicates each, after Piccapietra et $\mathrm{al}^{\left[{ }^{[43}\right]}$ ). Note that the total Ag exposure concentrations are much higher in the case of AgNP. The number of cellular bound AgNP was calculated as about 2 to 10 NP per cell and indicated a limited bioavailability of AgNP.

water composition and result in release of toxic $\mathrm{Ag}^{+}$ions, which may also be complexed with natural ligands. However, it must also be taken into account that AgNP may interact with sulfide present in wastewater treatment plants, as well as with low sulfide concentrations in natural waters. ${ }^{[4-46]}$ The formation of a silver sulfide layer at the surface of AgNP or the transformation of AgNP into $\mathrm{Ag}_{2} \mathrm{~S}_{(\mathrm{s})}$ would lead to decreased solubility and thus most probably to decreased toxicity. As shown above in exposure media, $\mathrm{CeO}_{2} \mathrm{NP}$ have a strong tendency for agglomeration in the presence of $\mathrm{Ca}^{2+}$ and $\mathrm{Mg}^{2+}$, but may be stabilized by phosphate, ${ }^{[22]}$ as well as possibly by dissolved organic matter. ${ }^{[47]}$ Reduction of $\mathrm{CeO}_{2} \mathrm{NP}$ to $\mathrm{Ce}(\mathrm{III})$ may occur under reducing conditions, e.g. in anoxic sediments, so that $\mathrm{Ce}$ (III) may be released into solution. $\mathrm{TiO}_{2} \mathrm{NP}$ are expected to strongly agglomerate in the presence of $\mathrm{Ca}^{2+}$ and $\mathrm{Mg}^{2+}$ at typical concentrations of freshwaters, but may be stabilized by dissolved organic matter. ${ }^{[24]}$ If these NP agglomerate to larger particle sizes (over $1 \mu \mathrm{m}$ ), they will rapidly settle to the benthic and sediment compartments and may thus affect benthic organisms. [23] ROS formation may occur under natural sunlight conditions.

\section{Conclusions and Outlook}

The discussed examples illustrate that detailed understanding of the chemical processes is essential to the study of ENP effects on aquatic organisms. Thorough characterization of ENP suspensions with respect to size, agglomeration state, dissolution and reactivity is a prerequisite for ecotoxicology studies that aim to understand mechanisms of action. In spite of rapid progress in this research area, some fundamental questions remain open, such as: In which organisms and under which conditions are nanoparticles taken up? Is internalization of nanoparticles in cells a prerequisite for toxicity or are nanoparticle effects in the external medium more important? How do nanoparticles interact at cell membranes? How can particle-specific effects be distinguished from effects of released metal ions in cells?

To further study these questions and improve our understanding of the processes and nanoparticle interactions at biological interfaces, novel methods of particle characterization and imaging have to be combined with biological methods and with molecular biology approaches. Further understanding of the factors which may either mitigate or enhance toxicity of ENP under natural water conditions must be pursued. Interdisciplinary collaboration is clearly of high importance for research in nanoecotoxicology.

\section{Acknowledgment}

We thank the Swiss National Science Foundation (SNF), the National Research Programme NRP 64, the Swiss Federal Office of the Environment (Bafu), and the German Federal Ministry of Education and Research for funding of this research.

Received: September 4, 2014

[1] S. J. Klaine, A. A. Koelmans, N. Horne, S. Carley, R. D. Handy, L. Kapustka, B. Nowack, F. von der Kammer, Environ. Toxicol. Chem. 2012, 31, 3.

[2] K. Schirmer, R. Behra, L. Sigg, M. J. F. Suter, in 'Safety aspects of engineered nanomaterials', Ed. W. Luther, A. Zweck. Pan Stanford: Singapore, 2013, p. 141.

[3] A. Kroll, D. Kühnel, K. Schirmer, in 'Oxidative Stress and Nanotechnology: Methods and Protocols', Ed. D. Armstrong, D. J. Bharali, Springer Science+Business Media: New York, 2013.
[4] A. Kahru, A. Ivask, Accounts Chem. Res. 2013, 46, 823.

[5] P. Westerhoff, B. Nowack, Accounts Chem. Res. 2013, 46, 844 .

[6] F. Gottschalk, T. Y. Sun, B. Nowack, Environ. Pollut. 2013, 181, 287.

[7] F. Gottschalk, B. Nowack, J. Environ. Monit. 2011, 13, 1145

[8] M. R. Wiesner, G. V. Lowry, P. Alvarez, D. Dionysiou, P. Biswas, Environ. Sci. Technol. 2006, 40, 4336.

[9] S. J. Klaine, P. J. J. Alvarez, G. E. Batley, T. F. Fernandes, R. D. Handy, D. Y. Lyon, S. Mahendra, M. J. McLaughlin, J. R. Lead, Environ. Toxicol. Chem. 2008, 27, 1825.

[10] E. Navarro, A. Baun, R. Behra, N. B. Hartmann, J. Filser, A. J. Miao, A. Quigg, P. H. Santschi, L. Sigg, Ecotoxicology 2008, 17, 372.

[11] O. Bondarenko, K. Juganson, A. Ivask, K. Kasemets, M. Mortimer, A. Kahru, Arch. Toxicol. 2013, 87, 1181.

[12] B. Nowack, J. F. Ranville, S. Diamond, J. A. Gallego-Urrea, C. Metcalfe, J. Rose, N. Horne, A. A. Koelmans, S. J. Klaine, Environ. Toxicol. Chem. 2012, 31, 50.

[13] F. Gottschalk, T. Sonderer, R. W. Scholz, B. Nowack, Environ. Sci. Technol. 2009, 43, 9216.

[14] F. Gottschalk, C. Ort, R. W. Scholz, B. Nowack, Environ. Pollut. 2011, 159, 3439.

[15] K. Schirmer, in 'Frontiers of Nanoscience', Ed. J. R. Lead, E. Valsami-Jones, Elsevier: Oxford, 2014, vol. 7, p. 195.

[16] R. Behra, L. Sigg, M. J. D. Clift, F. Herzog, M. Minghetti, B. Johnston, A. Petri-Fink, B. Rothen-Rutishauser, J. R. Soc. Interface 2013, 10, 20130396.

[17] H. Rauscher, G. Roebben, 'Towards a review of the EC recommendation for a definition of the term "nanomaterial", European Commission, Joint Research Centre: Luxembourg, 2014.

[18] J. Buffle, K. J. Wilkinson, S. Stoll, M. Filella, J. W. Zhang, Environ. Sci Technol. 1998, 32, 2887.

[19] F. Piccapietra, L. Sigg, R. Behra, Environ. Sci Technol. 2012, 46, 818.

[20] Y. Yue, R. Behra, L. Sigg, P. Fernandez Freire, S. Pillai, K. Schirmer, Nanotoxicology 2014, DOI: $10.3109 / 17435390.2014 .889236$

[21] K. Groh, T. Dalkvist, F. Piccapietra, R. Behra, M. Suter, K. Schirmer, Nanotoxicology 2014, DOI: $10.3109 / 17435390.2014 .893379$.

[22] L. A. Röhder, T. Brandt, L. Sigg, R. Behra, Aquat. Toxicol. 2014, 152, 121.

[23] H. Schug, C. W. Isaacson, L. Sigg, A. Ammann, 
K. Schirmer, Environ. Sci. Technol. 2014, 48, 11620.

[24] E. Topuz, L. Sigg, I. Talinli, Environ. Pollut. 2014, 193, 37

[25] P. G. C. Campbell, O. Errécalde, C. Fortin, V. P. Hiriart-Baer, B. Vigneault, Comp. Biochem. Physiol. Part C 2002, 133, 189.

[26] E. Navarro, F. Piccapietra, B. Wagner, F. Marconi, R. Kaegi, N. Odzak, L. Sigg, R. Behra, Environ. Sci Technol. 2008, 42, 8959.

[27] X. Yang, A. P. Gondikas, S. M. Marinakos, M. Auffan, J. Liu, H. Hsu-Kim, J. N. Meyer, Environ. Sci Technol. 2012, 46, 1119.

[28] R. A. Bell, J. R. Kramer, Environ. Toxicol. Chem. 1999, 18, 9 .

[29] A. P. Gondikas, A. Morris, B. C. Reinsch, S. M. Marinakos, G. V. Lowry, H. Hsu-Kim, Environ. Sci. Technol. 2012, 46, 7037.

[30] N. Odzak, D. Kistler, R. Behra, L. Sigg, Environ. Chem. 2014, doi: 10.1071/EN14049.

[31] S. A. Hayes, P. Yu, T. J. O'Keefe, M. J. O'Keefe, J. O. Stoffer, J. Electrochem. Soc. 2002, 149, C623.
[32] M. Baalousha, P. Le Coustumer, I. Jones, J. R. Lead, Environ. Chem. 2010, 7, 377.

[33] K. G. Knauss, M. J. Dibley, W. L. Bourcier, H. F. Shaw, Appl. Geochem. 2001, 16, 1115

[34] N. Odzak, D. Kistler, R. Behra, L. Sigg, Environ. Pollut. 2014, 191, 132.

[35] W. Davison, H. Zhang, Environ. Chem. 2012, 9 , 1.

[36] M. Auffan, J. Rose, M. R. Wiesner, J.-Y. Bottero, Environ. Pollut. 2009, 157, 1127.

[37] T. Xia, M. Kovochich, M. Liong, L. Mädler, B. Gilbert, H. Shi, J. I. Yeh, J. I. Zink, A. E. Nel, ACS nano 2008, 2, 2121.

[38] C. Kormann, D. W. Bahnemann, M. R. Hoffmann, Environ. Sci. Technol. 1991, 25, 494.

[39] A. S. Karakoti, S. Singh, A. Kumar, M. Malinska, S. V. N. T. Kuchibhatla, K. Wozniak, W. T. Self, S. Seal, J. Am. Chem. Soc. 2009, $131,14144$.

[40] C. Korsvik, S. Patil, S. Seal, W. T. Self, Chem. Commun. 2007, 1056.

[41] E. G. Heckert, S. Seal, W. T. Self, Environ. Sci Technol. 2008, 42, 5014.
[42] T. Pirmohamed, J. M. Dowding, S. Singh, B. Wasserman, E. Heckert, A. S. Karakoti, J. E. S. King, S. Seal, W. T. Self, Chem. Commun. 2010, 46, 2736.

[43] F. Piccapietra, C. Gil-Allué, L. Sigg, R. Behra, Environ. Sci Technol. 2012, 46, 7390.

[44] G. V. Lowry, B. P. Espinasse, A. R. Badireddy, C. J. Richardson, B. C. Reinsch, L. D. Bryant, A. J. Bone, A. Deonarine, S. Chae, M. Therezien, B. P. Colman, H. Hsu-Kim, E. S. Bernhardt, C. W. Matson, M. R. Wiesner, Environ. Sci Technol. 2012, 46, 7027.

[45] B. C. Reinsch, C. Levard, Z. Li, R. Ma, A Wise, K. B. Gregory, G. E. Brown, G. V. Lowry, Environ. Sci Technol. 2012, 46, 6992.

[46] C. Levard, B. C. Reinsch, F. M. Michel, C. Oumahi, G. V. Lowry, G. E. Brown, Environ. Sci Technol. 2011, 45, 5260.

[47] J. T. K. Quik, I. Lynch, K. Van Hoecke, C. J. H. Miermans, K. A. C. Schamphelaere, C. R. Janssen, K. A. Dawson, M. A. Cohen Stuart, D. Van den Meent, Chemosphere 2010, 81, 711. 